\title{
Paso Robles vineyard irrigation study provides benchmark data to assist future area groundwater management
}

\begin{abstract}
Researchers have identified baseline irrigation application data that can help groundwater sustainability agencies estimate regional irrigation usage for wine grape crops.
\end{abstract}

by Mark C. Battany and Gwen N. Tindula

\section{Abstract}

Accurate information on irrigation water usage does not exist in many areas where groundwater is the primary water source. This lack of information will hinder efforts to manage these groundwater basins sustainably according to current and future water regulations and policies. Using a low-cost methodology of irrigation-line pressure sensors connected to data loggers, we estimated irrigation applications at 84 vineyard sites in the Paso Robles Groundwater Basin over 4 years (20102013). We compared irrigation amounts with the preceding winter's rainfall and with the growing season reference evapotranspiration $\left(E T_{0}\right)$. Over the study period, the average annual irrigation application was 11.46 inches (291 millimeters). The average annual application correlated inversely to the preceding winter's rainfall, while the irrigation over the growing season (April-October) correlated directly with the $\mathrm{ET}_{\mathrm{o}}$ over this same period. This study provides an initial data framework that can be used by groundwater sustainability agencies to help manage groundwater in the Paso Robles area. The methodology also could be utilized in other regions to estimate regional irrigation usage while maintaining anonymity for participants.
- he recent passage of the Sustainable Groundwater Management Act (SGMA) in California obligates increased levels of management in high- and medium-priority groundwater basins in the near future in order to achieve long-term sustainable groundwater conditions (DWR 2014). An immediate challenge for effective management in many agricultural areas reliant upon groundwater is that little or no information currently exists on the amount of water extracted for irrigation at the individual farm level. Unlike users of developed surface water, growers who pump groundwater have generally never had to measure or report how much water they extract unless they are located in an adjudicated or actively managed basin.

This lack of information on how much water is extracted can become a major handicap for any agency tasked with managing the groundwater supply in the near future, before metering becomes more widespread. Accurate information on extraction amounts and how these amounts can vary from year to year as a function of rainfall conditions will be critical in order

Online: https://doi.org/10.3733/ca.2018a0003

In many agricultural areas reliant upon groundwater, such as the Paso Robles Groundwater Basin, there is little or no information on how much water is extracted for irrigation at the individual farm level, which makes it challenging for groundwater sustainability agencies to effectively manage groundwater supply. The authors present a low-cost monitoring approach that employs irrigation-line pressure sensors and data loggers.

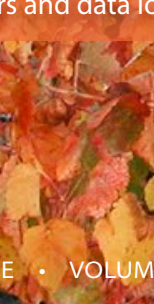


to create effective, sensible and fair groundwater management strategies. Having accurate water usage information will also ensure that groundwater modeling efforts will produce the most reliable output possible and thus serve as reliable tools for improving groundwater basin management.

The Paso Robles Groundwater Basin in San Luis Obispo County is classified as a high priority, critically overdrafted basin under SGMA, and is required to adopt a groundwater sustainability plan by January 2020 (DWR 2017) (a critically overdrafted basin is one in which continuing current management practices is likely to result in adverse environmental, social or economic impacts). The basin supports an important irrigated agricultural economy currently dominated by wine grape production. Earlier attempts to grow nonirrigated fruit crops in the region over a century ago largely failed, highlighting the importance of a reliable water supply (Shinn 1902). After the discovery of seemingly abundant groundwater, local crop production shifted to irrigated crops, including forage, alfalfa and sugar beets. In recent decades, the advent of pressurecompensating drip irrigation systems has enabled vineyard cultivation to occur on steeper terrain that was unsuited to earlier irrigation methods.

The region is relatively dry, with an average annual rainfall of 14.1 inches (in) (358 millimeters [mm]) in the city of Paso Robles since 1942 (Paso Robles Water Division 2014). Precipitation diminishes heading east from Paso Robles towards Shandon (Fugro West and Cleath 2002). Groundwater is virtually the only source of irrigation water for the basin area, as the developed surface water in the region is mostly devoted to local municipal use or for groundwater recharge in Monterey County to the north. Across the study region, the depth to groundwater below the surface is roughly several hundred feet. Even prior to the recent 5-year drought beginning in 2012, groundwater levels were observed to be declining in parts of the basin, suggesting that water extraction was exceeding recharge (City of Paso Robles 2011)

The lack of accurate information on agricultural pumping of groundwater has been a serious impediment to understanding the basin and predicting future trends. Vineyards are the dominant crop in the region and represent the largest single water extraction from the basin (Geoscience and Todd Groundwater 2014), and as such, errors in the estimate of annual vineyard irrigation applications may have large impacts on the accuracy of modeling efforts. Previous groundwater studies of the Paso Robles Groundwater Basin used theoretical estimates of vineyard irrigation, but no measured data was available to verify these estimates. A 2010 peer review of the previous studies indicated that improving the accuracy of the vineyard irrigation component was a major priority to improving the modeling results (Yates 2010).

The generic irrigation application values ascribed to vineyards in California had been utilized in the initial

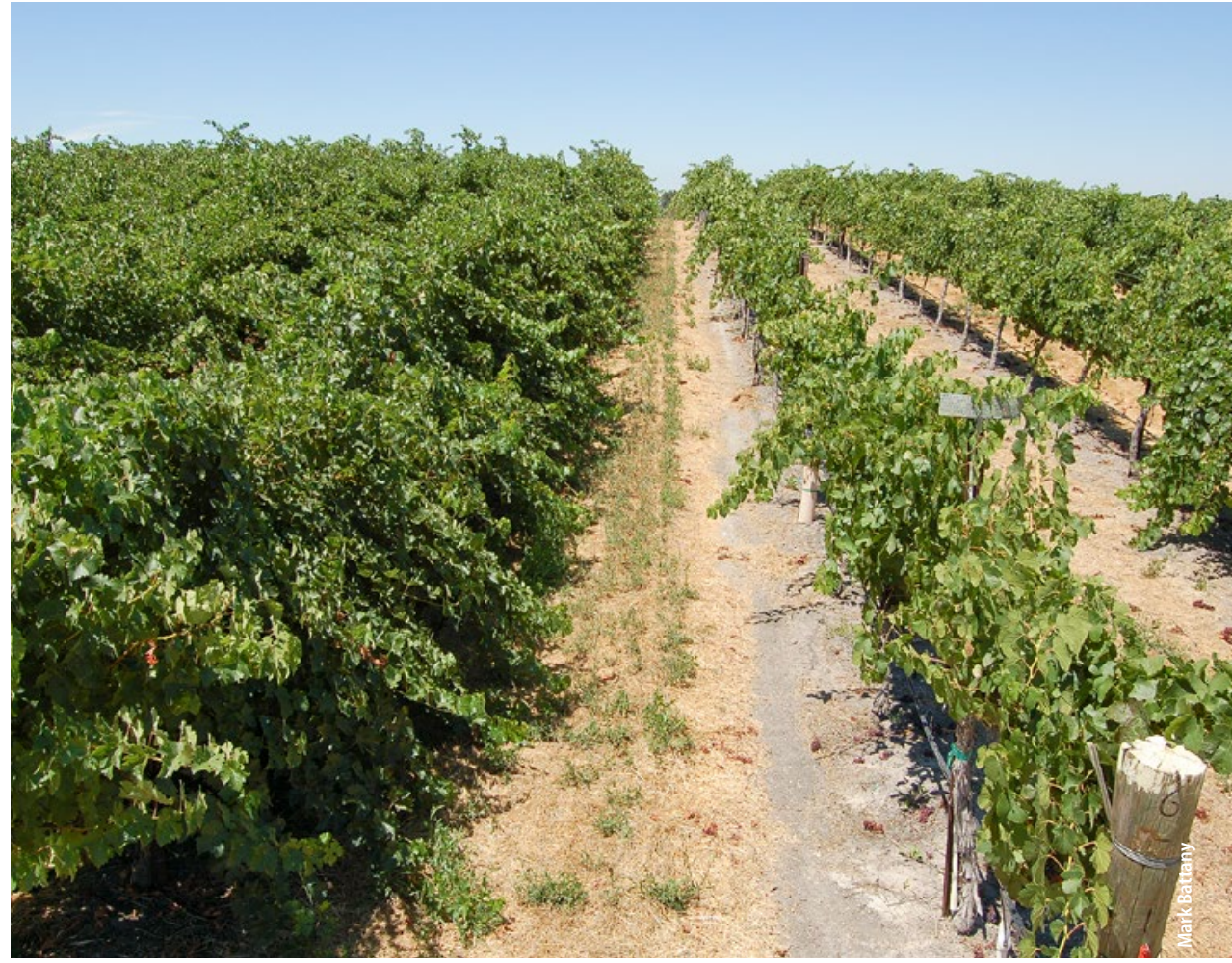

Different production styles

studies of groundwater conditions in the area, but it was unknown how representative these values were for local conditions. It was suspected that these values likely overestimated actual vineyard irrigation application, but no data was available to improve upon them. The 2012 San Luis Obispo County Master Water Report indicated an annual irrigation application of 1.7 feet $(518 \mathrm{~mm})$ as a "medium" value for the study region, but this type of theoretical estimate unavoidably makes many assumptions on irrigation management such as applied leaching fractions or levels of deficit irrigation; these may not hold true in actual practice (San Luis Obispo County 2012).

Another challenge in estimating annual irrigation applications in the region is that the style of wine grape production has evolved over time and irrigation technology has improved; both have implications for applied irrigation amounts. In the 1990s, the region was producing relatively high tonnages of fruit per acre; since that time there has been a steady decline in average production per acre, in part due to a shift in focus to producing higher quality crops at lower tonnages per acre (Battany 2015). This shift has generally been accompanied by a reduction in applied irrigation, as this is the main tool that growers have to control vineyard vegetative growth, and a reduced level of production requires less area of foliage. The increasing use of pressure-compensating drip emitters and tools such as soil moisture monitoring has likely increased application efficiencies over time as well. Thus, earlier estimations of applied irrigation may not address current wine grape production conditions and irrigation practices in the region. and goals - producing high tonnages of fruit per acre versus higher quality crops at lower tonnages per acre - result in vineyards that have very different canopy sizes and, therefore, different irrigation water requirements. The block on the left, for example, has a large amount of foliage and will need more irrigation than the block on the right. 
The purpose of this study was to develop a representative value of the annual vineyard irrigation water application in this region, and to determine how this amount varied in relation to the amount of rainfall that occurred in the preceding winter and to the reference evapotranspiration $\left(\mathrm{ET}_{\mathrm{o}}\right)$ during the current growing

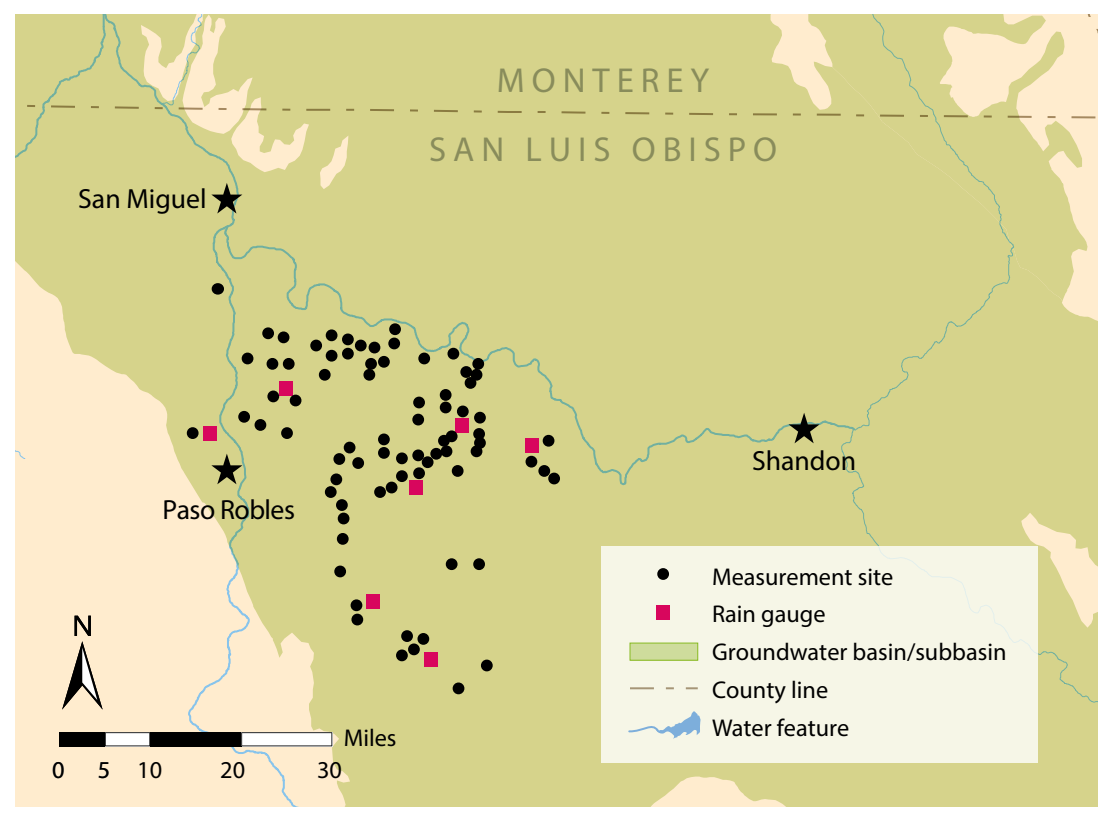

FIG. 1. The 84 study sites at vineyards across the Paso Robles Groundwater Basin. Source: DWR Bulletin 118 (DWR 2016).

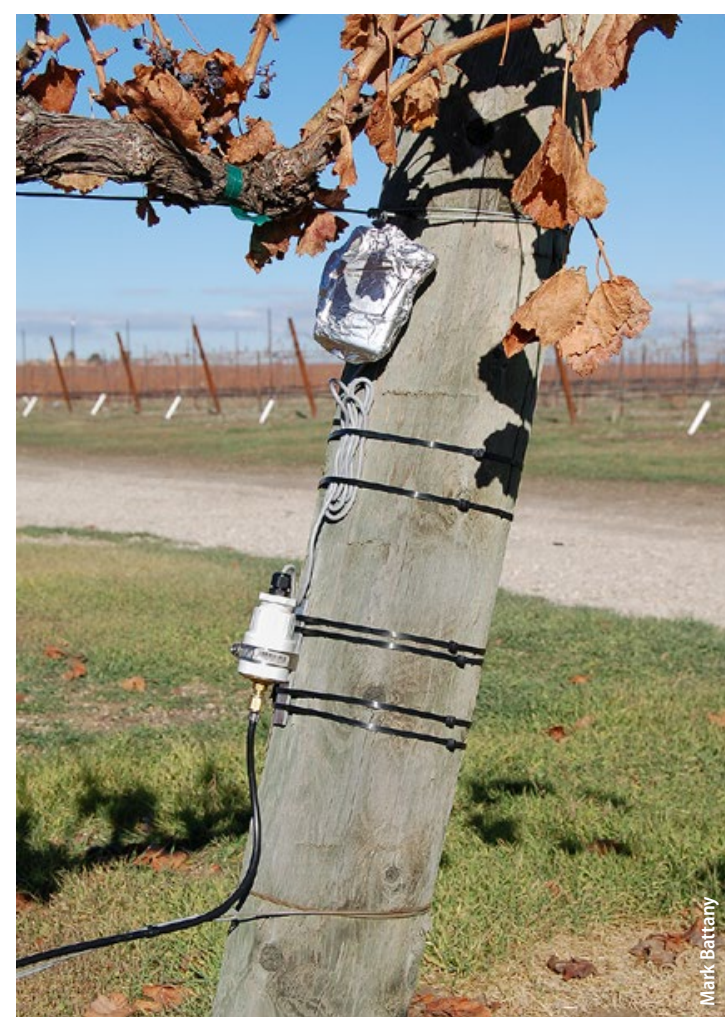

A pressure sensor and data logger in the field. The sensor is plumbed via the spaghetti line into the drip line, and the data logger is housed inside a waterproof container covered in aluminum foil. season. To our knowledge, the resulting dataset is the only large-scale collection to date of direct measurements of agricultural groundwater use in this region; as such, it provides important baseline information for groundwater management under SGMA.

\section{The study approach}

Measurements were made at 84 vineyard blocks in the western portion of the basin (fig. 1). At the time that we initiated the study, this specific area was considered to be the primary region of declining groundwater levels in the basin, based on groundwater level changes between 1997 and 2009 (City of Paso Robles 2011). We chose sampled vineyard blocks at random from all of the blocks on a participating property, with one block chosen for each 100 acres (40 hectares) of planted vineyard area on that property. All sampled blocks were mature and producing fruit; one block was grafted over during the study period, and none were removed.

In each sampled block a pressure switch with a 4 psi $(28 \mathrm{kPa})$ activation pressure (5000 series switch, part number 76575, Honeywell Corporation, Morristown, $\mathrm{NJ}$ ) was plumbed into the irrigation drip line with a separate spaghetti line. This sensor was read continuously with a small Hobo State data logger (Onset Computer Corporation, Bourne, MA) to record the irrigation system run time. This run time information, multiplied by the value of the design flow of the

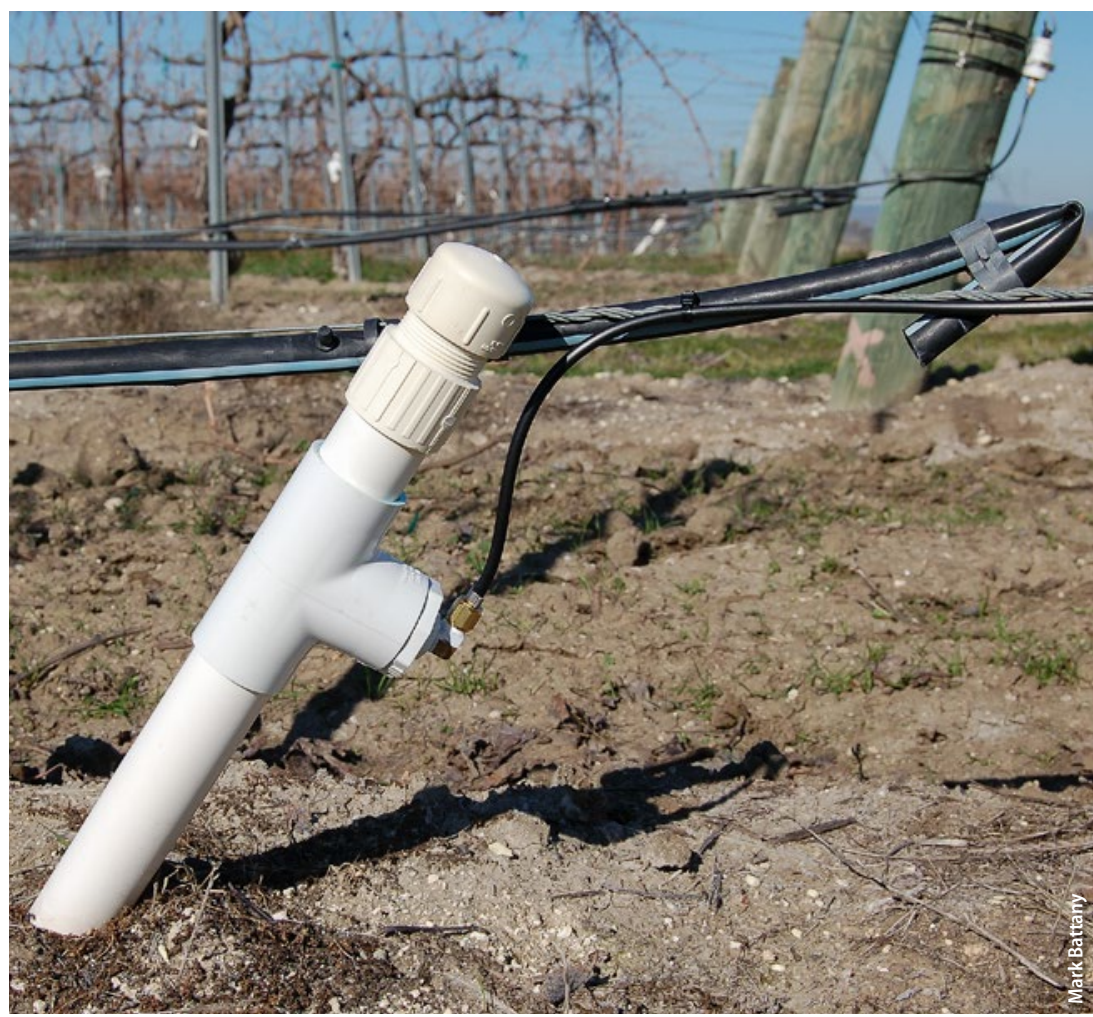

Twenty-two of the 84 sites had sprinkler systems in addition to drip lines. To determine water applied over time for these systems separately, a second pressure sensor and data logger were attached to a sprinkler riser or cleanout line, as shown above. 
corresponding block, produced an estimate of the volume of water applied over time. At sites with sprinklers in addition to drip lines, we installed a second data logger and pressure switch unit and used a similar calculation method to determine water applied over time for this system separately. Twenty-two of the 84 locations had sprinklers; some were utilized for springtime frost protection, while others had been installed solely to provide supplemental irrigation in the winter.

The measurement devices were installed in the fall of 2009 and irrigation data was collected over four complete calendar years from 2010 through 2013. A set of seven recording rain gauges was also installed throughout the study area before the winter rainfall period began in late 2009 , and these seven gauges were operated over the same time period. The $\mathrm{ET}_{\mathrm{o}}$ values are from the California Department of Water Resources Spatial CIMIS program, calculated for the Paso Robles Airport location; the nearest CIMIS weather station (\#163) is located approximately 16 miles $(27 \mathrm{~km})$ to the south in Atascadero.

The fundamental assumption with this method measuring the duration for which the irrigation system is pressurized and then multiplying this time by the design flow - is that the actual flow rate that occurs with the system is the same as the design flow rate (e.g., the rate indicated on the emitters). There are many reasons why the actual flow rate may differ from the design flow rate: inadequate or excessive system pressure, clogging, wear, broken or missing components, or leaks. However, the assumption that the actual flow and design flow are very similar in the aggregate for larger sample sizes is supported by long-term drip irrigation system test data. For example, in 113 evaluations between 1995 and 2008 of drip irrigation systems using nominal 0.5 gallon (1.89 liters) per hour emitters, the mean measured flow rate was 0.504 gallons (1.91 liters) per hour (Cal Poly ITRC 2010). The alternative of installing flow meters at the pumping wells that did not already have them would have been prohibitively expensive and itself also subject to considerable potential errors (Hanson and Schwankl 1998). It also would have required the measurement of irrigation applications in all of the vineyard blocks served by that well in order to be able to correlate flow meter readings to the particular block of interest in this study. Additionally, among potential cooperators there was very strong hesitation to allow measurements of pump flow meters, while the measurements of single vineyard blocks were more acceptable.

A major challenge with this type of research project, which needs to be conducted on private property, is that some growers simply do not want their water usage measured for any reason. Growers in the area have had concerns about potential groundwater basin adjudication that might limit their future access to water; as a result, they have been hesitant to divulge any information about pumping that might somehow be used against them in the future. To make participation in this project as palatable as possible in order to achieve a sufficient number of participating growers, we devised a data management method that ensured anonymity of the irrigation application information. This was accomplished by using random site codes that were destroyed each year after a previous calendar year's data was downloaded in early January and the necessary calculations were performed. This assurance of data privacy was a key factor in achieving a broad level of participation in this study. Because the goal of the project was to generate an understanding of how the regional industry as a whole utilized irrigation water rather than what individual users themselves did, this was a very worthwhile concession to make in order to secure broad voluntary participation.

\section{The findings}

Wine grape production in this region is dominated by the variety cabernet sauvignon, which accounted for over half of the study sites selected (table 1). Other major varieties included merlot, zinfandel and syrah, and a number of minor varieties were also included.

A variety of vine training (trellis) systems are utilized in the area, and these were represented in the study sites (table 2); for a description of trellis types see Christensen et al. 2003. The vertically shoot positioned (VSP) system predominated at the study sites. The distinction between a VSP and hybrid-VSP system can be somewhat arbitrary, as there is a continuum of management styles with this basic trellis system that involves positioning a varying percentage of the shoots in different manners. The summary vineyard planting

TABLE 1. Wine grape varieties for all of the measurement sites in the Paso Robles Groundwater Basin

\begin{tabular}{|l|c|c|}
\hline Variety & Number of sites & Percentage \\
\hline Cabernet sauvignon & 47 & $56 \%$ \\
\hline Merlot & 11 & $13 \%$ \\
\hline Zinfandel & 8 & $10 \%$ \\
\hline Syrah & 5 & $6 \%$ \\
\hline Other* & 13 & $15 \%$ \\
\hline * Cabernet franc, chardonnay, grenache, petite sirah, petit verdot, sangiovese, sauvignon blanc, and tempranillo.
\end{tabular}

TABLE 2. Training systems at the measurement sites in the Paso Robles Groundwater Basin

\begin{tabular}{|c|c|c|}
\hline Training system & Number of sites & Percentage \\
\hline $\begin{array}{l}\text { Vertically shoot positioned } \\
\text { (VSP) }\end{array}$ & 40 & $48 \%$ \\
\hline Sprawl & 20 & $24 \%$ \\
\hline Hybrid VSP-sprawl* & 12 & $14 \%$ \\
\hline Quadrilateral & 11 & $13 \%$ \\
\hline Lyre & 1 & $1 \%$ \\
\hline
\end{tabular}


TABLE 3. Vineyard planting dimensions

\begin{tabular}{|l|c|c|c|c|}
\hline Parameter & Mean & $\begin{array}{c}\text { Standard } \\
\text { deviation }\end{array}$ & Maximum & Minimum \\
\hline Row spacing, $\mathrm{ft}(\mathrm{m})$ & $9.5(2.9)$ & $1.2(0.37)$ & $11.5(3.5)$ & $6.0(1.8)$ \\
\hline Vine spacing, $\mathrm{ft}(\mathrm{m})$ & $6.3(1.9)$ & $0.7(0.21)$ & $8.0(2.4)$ & $4.0(1.2)$ \\
\hline
\end{tabular}

TABLE 4. Annual average irrigation applications and rainfall, 2010-2013

\begin{tabular}{|l|c|c|c|c|c|}
\hline & \multicolumn{5}{c}{ Irrigation } \\
\hline & $\begin{array}{c}\text { Annual } \\
\text { average }\end{array}$ & $\begin{array}{c}\text { Standard } \\
\text { deviation }\end{array}$ & Maximum & Minimum & $\begin{array}{c}\text { Preceding } \\
\text { winter } \\
\text { rainfall }\end{array}$ \\
\hline Year & & & in (mm) & & \\
\hline 2010 & $10.35(263)$ & $5.39(137)$ & $27.01(686)$ & $3.07(78)$ & $16.30(414)$ \\
\hline 2011 & $8.43(214)$ & $4.76(121)$ & $24.76(629)$ & $2.13(54)$ & $21.61(549)$ \\
\hline 2012 & $12.05(306)$ & $4.84(123)$ & $28.15(715)$ & $2.72(69)$ & $8.31(211)$ \\
\hline 2013 & $14.96(380)$ & $5.47(139)$ & $32.01(813)$ & $5.43(138)$ & $5.51(140)$ \\
\hline Overall average & $11.46(291)$ & & & & $12.91(328)$ \\
\hline
\end{tabular}

dimensions represent moderate-density plantings typical of the region (table 3 ).

The four study years encompassed two seasons of above-average rainfall and two seasons of belowaverage rainfall (table 4 ). The average annual irrigation application over the 4 years was 11.46 in $(291 \mathrm{~mm})$. The variation in the total amount of annual irrigation that is applied at different vineyards in the region in a given year is quite large, as indicated by the large standard deviation relative to the mean value. The maximum values each year are more than twice the average, and the minimum values are less than half the average. Numerous factors determine how much irrigation is applied to a given vineyard; this includes the amount of winter rainfall at that specific site, the soil water holding capacity, the management of cover crops, the particular rootstock and its rooting depth, the salinity conditions, the row spacing and type of trellis

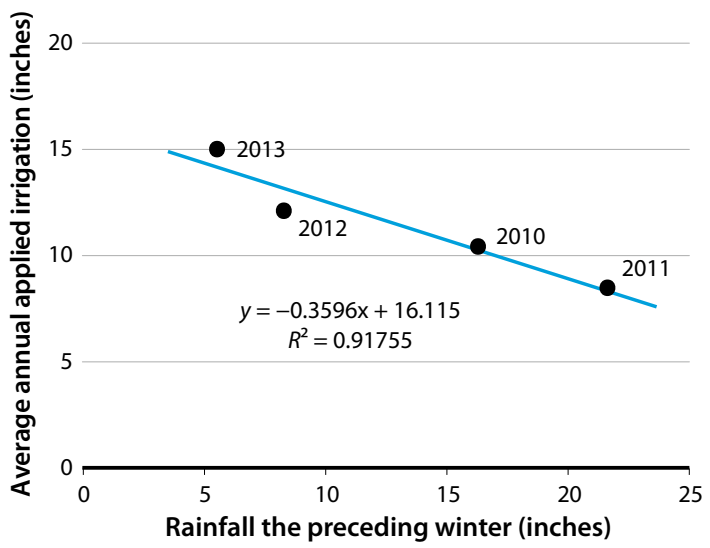

FIG. 2. Relationship between the amounts of rainfall the preceding winter and the total irrigation applied in the calendar year. The rainfall is the average of the seven gauges over the study area. (which both influence the total amount of vegetative growth), and the fruit production goals, among others. Considering the wide range of these factors, there is no single strategy for managing irrigation or no single amount of irrigation that will suit all sites equally well; this variability in irrigation application creates an additional challenge for groundwater sustainability agencies (GSAs), which the SGMA has tasked with managing groundwater usage.

The relationship between the total rainfall during the preceding winter (average of the seven rain gauges) and the total applied irrigation in the calendar year shows a trend of diminishing irrigation applications following winters with higher precipitation (fig. 2). Each additional unit of rainfall in the preceding winter reduces the subsequent irrigation in the calendar year by 0.36 units. While this may seem like a very intuitive finding, having an equation to precisely describe this relationship is very useful because it can be used as a tool by management agencies that need to predict and potentially allocate pumping amounts as early as possible in the growing season.

The typical growing season for grapes in this area encompasses the months of April through October. The $\mathrm{ET}_{\mathrm{o}}$ and applied irrigation during this period varied by year (table 4 ). In addition to the rainfall during the winter prior to the growing season, the $\mathrm{ET}_{\mathrm{o}}$ conditions also influenced the amount of irrigation applied during the growing season, with larger amounts of irrigation applied as $\mathrm{ET}_{\mathrm{o}}$ increased (fig. 3).

Annual cumulative applied irrigation, expressed as the average of all sites over the calendar year, indicates how the wet and dry years differed in the timing of irrigation applications over the year (fig. 4). The two drier years $(2012,2013)$ stand out for the amount of irrigation applied during January, February and March, before bud break; growers were making up for the lack of rainfall with this winter irrigation. When winter rainfall was more abundant $(2010,2011)$, little to no winter irrigation was applied. The slopes of the curves

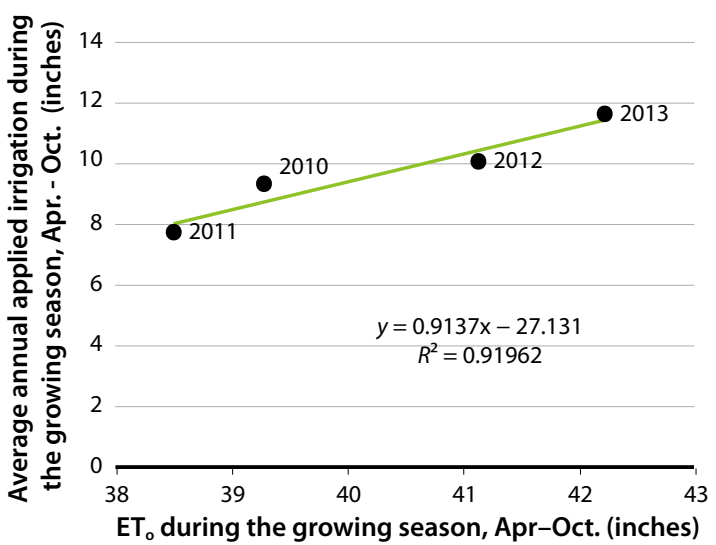

FIG. 3. Relationship between growing season (AprilOctober) $\mathrm{ET}_{\mathrm{o}}$ and irrigation applied during the growing season. 
from May through September are very similar for 2010, 2012 and 2013 with an average value of $1.68 \mathrm{in} /$ month (43 mm/month), indicating that once irrigation applications begin in earnest, the average monthly application amount does not vary much from year to year. An exception was observed for 2011, which had a shallower slope (1.28 in/month [32 $\mathrm{mm} / \mathrm{month}])$, indicating less application of irrigation over the May-September period. The 2011 season had both the greatest amount of preceding winter rainfall (table 4 ) and the lowest $\mathrm{ET}_{\mathrm{o}}$ value during the growing season (table 5).

The amount of irrigation applied relative to the $\mathrm{ET}_{\mathrm{o}}$ throughout the growing season is not constant (fig. 5). The leaf canopy will be essentially fully grown by June, and thus vine water requirements from June through October are in theory a constant percentage of the $\mathrm{ET}_{\mathrm{o}}$. In practice, however, less irrigation is applied in June and July relative to $\mathrm{ET}_{\mathrm{o}}$, as compared to August and September. Two reasons help explain this: after fruit set in late May or early June, more severe deficit irrigation is used to help slow down foliage growth and to keep developing berry sizes small; and deeper soil moisture from winter rainfall is often still available to the vines. By August and September, the deeper soil moisture from earlier rainfall is becoming depleted, and the deficit irrigation is eased up to help maintain functional leaf canopies. This pattern is reflected in the lower values of "Irrigation/ET," for June and July as compared to August and September (fig. 5).

\section{Implications}

The average annual irrigation application identified in this study is lower than the estimates that had been previously used in the region. The relatively low irrigation application demonstrates the suitability of wine grapes as a crop in areas with limited water availability, as the historical irrigated field crops in the region required far more irrigation water per acre and produced much lower value crops. The current relatively low average application of irrigation per acre suggests that there is not much room to save water by cutting back on applications without experiencing some level of yield loss as a result (Williams et al. 2010). The economic conditions of wine grape production in the region have not been favorable for many growers over the past decade, so reducing production levels without a commensurate increase in crop value would be unpopular (Battany 2015).

One reason why previous estimates of irrigation usage in the region may have been considerably higher than what was observed in this study was the assumption that leaching fractions were used to help remove accumulated salts from the root zone. Groundwater in the region varies widely in quality; an earlier study evaluating water quality from 16 wells in the study region observed electrical conductivity $\left(\mathrm{EC}_{\mathrm{e}}\right)$ ranging from 0.52 to 2.38 deciSiemens per meter $(\mathrm{dS} / \mathrm{m}$ ) (Fugro West and Cleath 2000). In order to save water or reduce

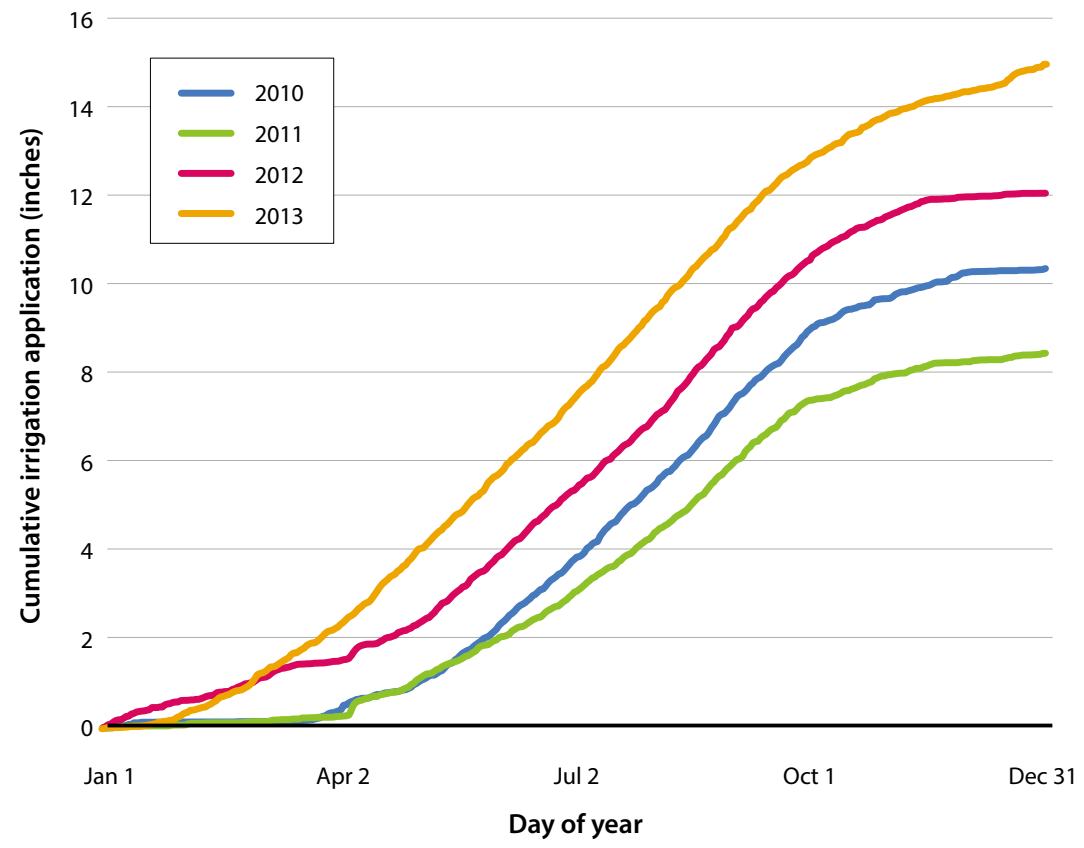

FIG. 4. Average cumulative irrigation application for each calendar year.

TABLE 5. Growing season (Apr-Oct) $\mathrm{ET}_{\mathrm{O}}$ and applied irrigation during the growing season

\begin{tabular}{|c|c|c|c|}
\hline Year & $\mathrm{ET}_{\mathrm{o}}$ & $\begin{array}{l}\text { Irrigation } \\
\text { in }(m m)\end{array}$ & Irrigation/ET \\
\hline 2010 & 39.3 (998) & $9.3(237)$ & 0.24 \\
\hline 2011 & 38.5 (978) & $7.7(196)$ & 0.20 \\
\hline 2012 & $41.1(1045)$ & $10.0(255)$ & 0.24 \\
\hline 2013 & $42.2(1072)$ & $11.6(295)$ & 0.28 \\
\hline
\end{tabular}

$8 \longrightarrow 0.35$

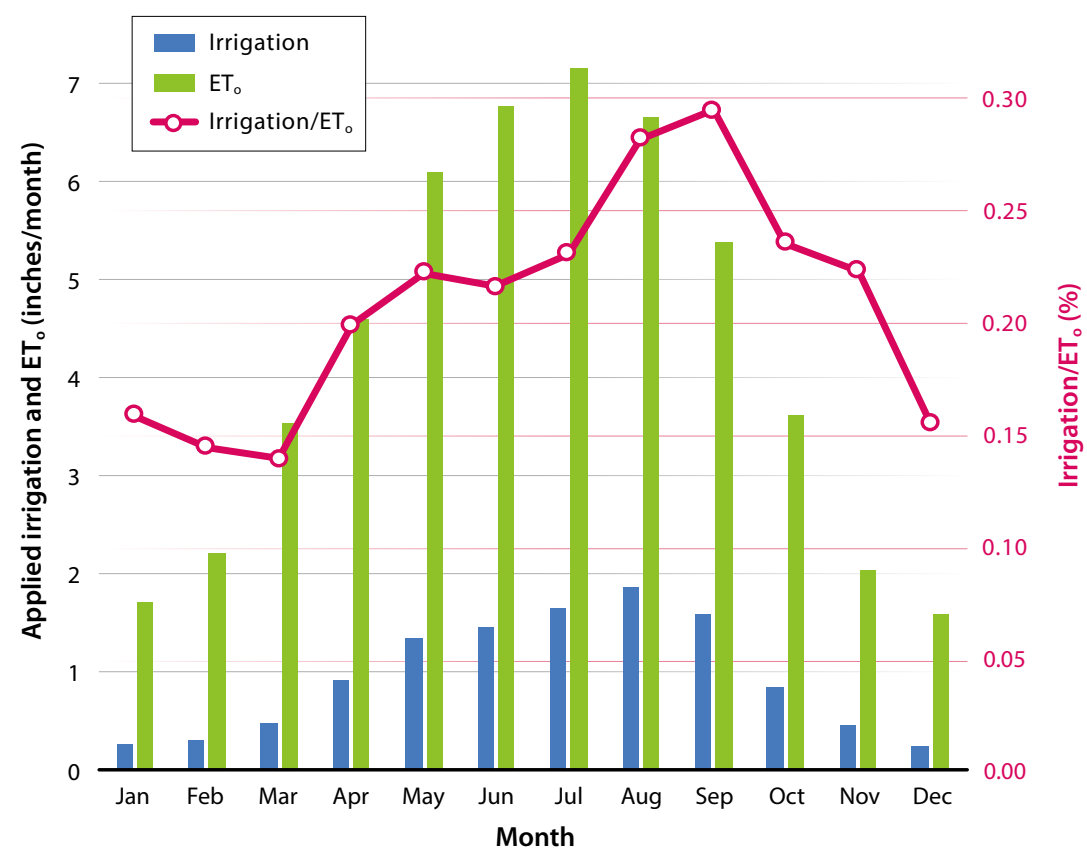

FIG. 5. The average monthly irrigation compared to the average monthly $\mathrm{ET}_{\mathrm{o}}$ over the 4-year period. 


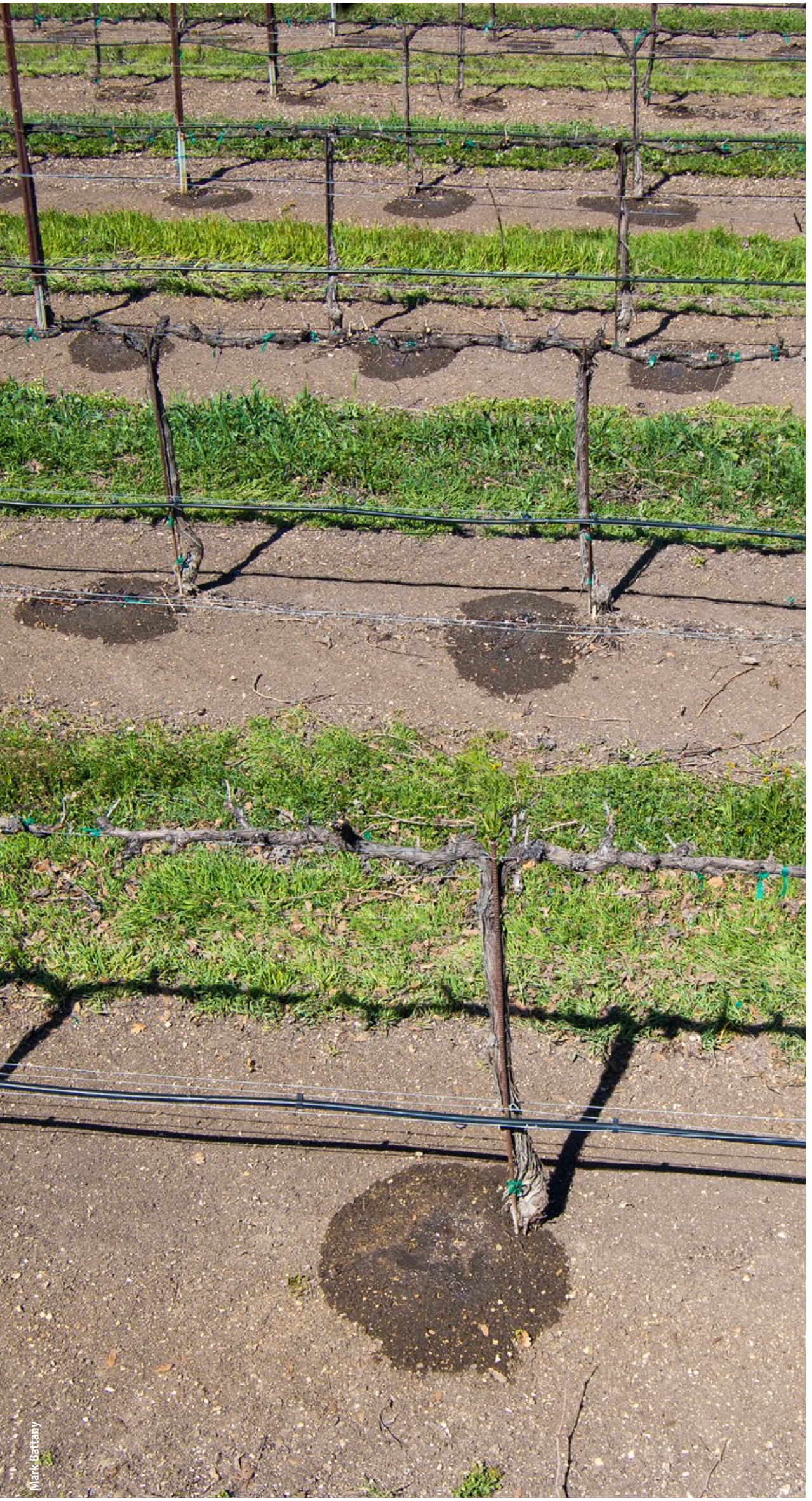

The relatively low irrigation application demonstrates the suitability of wine grapes as a crop in areas with limited water availability, as the historical irrigated field crops in the region required far more irrigation water per acre and produced much lower value crops.

costs, some growers may not be applying sufficient leaching fractions, and as a result may be experiencing increased salt accumulation in their soils; this pattern of increasing salt accumulations has been observed in the region (Battany 2011). Excessive soil salinity is an issue at numerous sites in the area, particularly those that were planted in past decades before the more salt-tolerant rootstocks became available. Wine grapes (Vitis vinifera) are classed as moderately sensitive to soil salinity, having a threshold soil $\mathrm{EC}_{\mathrm{e}}$ of 1.5 $\mathrm{dS} / \mathrm{m}$; soil salinity levels greater than this value will result in diminishing productivity (Grieve et al. 2012). Rootstocks with greater salt tolerance such as 1103 Paulsen have higher threshold $\mathrm{EC}_{\mathrm{e}}$ values and are now being widely planted. One reason why some growers have added supplemental sprinkler irrigation to their vineyards in the region is to have another tool for helping manage soil salinity.

\section{Data utilization for modeling}

Past modeling efforts of the Paso Robles Groundwater Basin have been hampered by the lack of accurate information on agricultural pumping from the basin. As this is the largest single discharge of water from the basin, errors in the estimates can lead to significant errors in the overall modeling results. In 2014, an update to the Paso Robles Groundwater Basin model was prepared for San Luis Obispo County as a refinement over the previous 2005 model (Fugro West et al. 2005; Geoscience and Todd Groundwater 2014). The daily values of average vineyard irrigation applications from this research project were utilized in the calibration of the vineyard irrigation portion of this model, providing valuable feedback to further refine the accuracy of the model parameters. Accurate groundwater basin models

The relatively low average application of irrigation per acre identified in the study was lower than the estimates that had been used previously in the region. This demonstrates the importance of generating more accurate estimates of irrigation applications based on comprehensive field measurements whenever possible. 
will be a key tool for future management of the basins; thus, having accurate data to construct them will be a high priority in many areas.

\section{Potential for real-time management}

As GSAs are formed in areas of high- and mediumpriority basins, one of the first steps that these agencies will likely take is to require the installation of flow meters on all irrigation wells. If these flow meters are equipped with an automated data delivery system that allows the GSA to have real-time pumping information, this in turn can be expressed as irrigation amounts per acre, and this information may be very useful for irrigation management. Irrigators all make challenging decisions as to how much water to apply and when, but it is unlikely that anyone gets this exactly right every season. The collective information sourced from a large community of growers all facing similar growing conditions may benefit from the phenomenon of the "wisdom of crowds," in which collective knowledge may sometimes be better than any single individual's knowledge (Surowiecki 2005). Thus, the types of curves shown in figure 4 , if shared in real time during a growing season, may have value as an irrigation index that growers could refer to for guidance on their own irrigation decisions. This could have particular value for smaller growers with limited management resources or for those with very limited experience in the region.

\section{Conclusions}

The GSAs that are being formed in California face a big challenge in developing programs that lead to sustainable groundwater management. A key tool for any GSA will be to have comprehensive data on representative irrigation water applications for key crops, and how this application amount responds to varying rainfall and evapotranspiration conditions from year to year. This project has produced such baseline irrigation application data for the wine grape crops grown in the area east of Paso Robles; these results can now be used by the area GSAs as a benchmark in their decision-making processes. The approach and methodology used in this study may have applications for developing estimates of typical irrigation applications over multiple years in other regions to help create benchmarks for groundwater management in those regions as well. CA

M.C. Battany is UC Cooperative Extension (UCCE) Viticulture Farm Advisor, San Luis Obispo and Santa Barbara counties; and G.N. Tindula was UCCE Staff Research Associate, San Luis Obispo, and is now Graduate Student at UC Berkeley.

The Paso Robles Wine Country Alliance supported this work with a $\$ 13,600$ donation to purchase required supplies; their support is appreciated. This project was also supported with funding from the 2012 CDFA Specialty Crop Block Grant program.

\section{References}

Battany MC. 2011. Evaluations of soil salinity conditions in California Central Coast winegrape vineyards. In: Proceedings of the Western Nutrient Management Conference, March 3-4, 2011. Reno, NV. 9:10-5.

Battany MC. 2015. Produc tion and economic trends for SLO County vineyards. Grape Notes Blog. http://ucanr.edu/ blogs/blogcore/postdetail. cfm?postnum $=18590$ (accessed Sept. 26, 2017)

[Cal Poly ITRC] Cal Poly Irrigation Training \& Research Center. 2010. Irrigation Evaluation Data, Drip/Micro. www.itrc.org/irrevaldata/index.php (accessed Sept. 26, 2017)

Christensen LP, Dokoozlian NK, Walker MA, Wolpert JA. 2003. Wine Grape Varieties in California. UC Agriculture and Natural Resources Publication 3419.

City of Paso Robles. 2011. Annual Monitoring Report for Calendar Year 2009. http://pasobasin.org/technical-studies/ (accessed Sept. 26, 2017).
[DWR] California Department of Water Resources. 2014. Sustainable Groundwater Management. http://groundwater ca.gov/ (accessed Sept. 26, 2017).

DWR. 2016. Bulletin 118, Interim Update 2016. California's Groundwater: Working Toward Sustainability. www. water.ca.gov/groundwater/ bulletin118/docs/Bulletin_118 Interim Update 2016.pdf (accessed Sept. 26, 2017).

DWR. 2017. Sustainable Groundwater Management: Critically Overdrafted Basins. www.water. ca.gov/groundwater/sgm/cod. cfm (accessed Sept. 26, 2017).

Fugro West Inc. and Cleath \& Associates. 2002. Final Report, Paso Robles Groundwater Basin Study. www.slocountywater. org/site/Water\%20Resources/ Water\%20Forum/pdf/Paso\%20 Robles\%20Groundwater\%20 Basin\%20Study,\%20Phase\%20l. pdf (accessed Sept. 26, 2017).
Geoscience and Todd Groundwater 2014. Paso Robles Groundwater Basin Model Update. www.slocountywater. org/site/Water\%20Resources/ Water\%20Forum/Computer\%20 Modeling/ (accessed Sept. 26 2017).

Grieve CM, Grattan SR, Maas EV 2012. Plant salt tolerance. In: Wallender WW, Tanji KK (eds.) Agricultural Salinity Assessment and Management (2nd ed.). ASCE Manual and Reports on Engineering Practice No. 71. Reston, VA: ASCE.

Hanson BR, SchwankI LJ. 1998 Water turbulence disrupts accuracy of some flow meters. Calif Agr 52(1):25-30. https://do org/10.3733/ca.v052n01p25

Paso Robles Water Division. 2014. Rainfall totals, 1942-2014. www.prcity.com/government/ departments/publicworks/water/rainfall.asp (accessed Sept. 26, 2017)
San Luis Obispo County. 2012 Master Water Report Volume III, May 2012. www.slocounty water.org/site/Frequent Downloads/Master Water Plan/pdf/ Vol_III_MWR final.pdf

Shinn CH. 1902. Experiments with Deciduous Fruits at and Near the Southern Coast Range Sub-Station, Paso Robles from 1889 to 1902 . University of California Bulletin No. 141.

Surowieki J. 2005. The Wisdom of Crowds. New York, NY: Anchor Books. $336 \mathrm{p}$.

Williams LE, Grimes DW, Phene CJ. 2010. The effects of applied water at various fractions of measured evapotranspiration on reproductive growth and water productivity of Thompson Seedless grapevines. Irrigation Sci 28:233-43.
Yates G. 2010. Peer Review of Paso Robles Groundwater Studies. Executive Summary. www.slocountywater.org/site/ Water\%20Resources/Water\%20 Forum/pdf/GW\%20Basin\%20 Peer\%20Review\%20Final\%20 Sec.pdf 